\title{
Sustained attention and serotonin: a pharmaco-fMRI study
}

Citation for published version (APA):

Wingen, M., Kuypers, K. P. C., van de Ven, V. G., Formisano, E., \& Ramaekers, J. G. (2008). Sustained attention and serotonin: a pharmaco-fMRI study. Human Psychopharmacology-Clinical and Experimental, 23(3), 221-230. https://doi.org/10.1002/hup.923

Document status and date:

Published: 01/01/2008

DOI:

10.1002/hup.923

Document Version:

Publisher's PDF, also known as Version of record

\section{Document license:}

Taverne

\section{Please check the document version of this publication:}

- A submitted manuscript is the version of the article upon submission and before peer-review. There can be important differences between the submitted version and the official published version of record.

People interested in the research are advised to contact the author for the final version of the publication, or visit the DOI to the publisher's website.

- The final author version and the galley proof are versions of the publication after peer review.

- The final published version features the final layout of the paper including the volume, issue and page numbers.

Link to publication

\footnotetext{
General rights rights.

- You may freely distribute the URL identifying the publication in the public portal. please follow below link for the End User Agreement:

www.umlib.nl/taverne-license

Take down policy

If you believe that this document breaches copyright please contact us at:

repository@maastrichtuniversity.nl

providing details and we will investigate your claim.
}

Copyright and moral rights for the publications made accessible in the public portal are retained by the authors and/or other copyright owners and it is a condition of accessing publications that users recognise and abide by the legal requirements associated with these

- Users may download and print one copy of any publication from the public portal for the purpose of private study or research.

- You may not further distribute the material or use it for any profit-making activity or commercial gain

If the publication is distributed under the terms of Article $25 \mathrm{fa}$ of the Dutch Copyright Act, indicated by the "Taverne" license above, 


\title{
Sustained attention and serotonin: a pharmaco-fMRI study
}

\author{
Marleen Wingen ${ }^{1}$, Kim P.C. Kuypers ${ }^{1}$, Vincent van de Ven $^{2}$, Elia Formisano ${ }^{2}$ \\ and Johannes G. Ramaekers ${ }^{1 *}$ \\ ${ }^{1}$ Department of Neuropsychology \& Psychopharmacology, Faculty of Psychology, Maastricht University, The Netherlands \\ ${ }^{2}$ Department of Neurocognition, Faculty of Psychology, Maastricht University, The Netherlands
}

\begin{abstract}
Objective Evidence suggests that stimulation of serotonergic function in healthy humans causes an impairment of sustained attention. The present study assessed the influence of increased serotonin levels on brain areas involved in sustained attention.

Methods Ten healthy volunteers $(5 \circ, 5 \hat{)})$ received the selective serotonin reuptake inhibitor (SSRI) escitalopram (20 mg) and placebo in a balanced, double blind, two-way crossover design. Participants performed the Mackworth Clock Test to measure sustained attention during functional MRI measurements at 3 Tesla. Subjective measurements after pharmacological manipulation were conducted with the Bond and Lader Questionnaire.

Results Independent of treatment, brain areas associated with task performance on a sustained attention task were activated, including right prefrontal and parietal areas. After escitalopram administration, less activation was shown in the caudate nucleus, thalamus, and frontal areas. No effect of escitalopram was shown on behavioral data although subjective measurements showed decreased alertness after escitalopram.

Conclusions The results of the current pharmaco-functional magnetic resonance imaging (fMRI) study give a first indication of involvement of serotonin in sustained attention through modulating activation of selective brain areas including the thalamus and caudate nucleus. Possibly, these areas are involved in a subcortical network for sustained attention, but further research is necessary. Copyright (C) 2008 John Wiley \& Sons, Ltd.
\end{abstract}

KEY WORDS - serotonin; sustained attention; pharmaco-fMRI

\section{INTRODUCTION}

The neurotransmitter serotonin is involved in different psychiatric disorders, including major depression. The majority of patients diagnosed with a depressive disorder have a malfunction of the serotonergic system (Meltzer, 1989). Depression and also other psychiatric disorders are associated with cognitive dysfunction such as impaired memory performance and attention or planning deficits (Elliott et al., 1997; Austin et al., 2001; Landro et al., 2001). There is evidence that serotonin plays a role in the etiology of depression and is associated with cognitive problems (reviewed by Schmitt et al., 2006). Some studies in depressed

\footnotetext{
* Correspondence to: J. G. Ramaekers, Department of Neuropsychology \& Psychopharmacology, Faculty of Psychology, Maastricht University, P.O. Box 616, 6200 MD Maastricht, The Netherlands. Tel: +31433881951 . Fax +31433884125 .

E-mail: j.ramaekers@psychology.unimaas.nl
}

patients showed that serotonin stimulation by antidepressants such as fluoxetine, fluvoxamine, and trazodone directly improves cognitive functions independent of elevation of depressive symptoms (Doraiswamy et al., 2003; Koetsier et al., 2002; Riedel et al., 1999b). Studies in healthy volunteers have also provided evidence for a possible role of serotonin in cognitive performance. Both low serotonin levels following tryptophan depletion and high serotonin levels following selective serotonin reuptake inhibitor (SSRI) administration have been shown to reduce memory performance (Riedel et al., 1999a; Riedel et al., 2002; Wingen et al., 2006b). It has been suggested that the relation between serotonin and memory reflects an inverted U-curve (Meeter et al., 2006) which entails that both overstimulation and understimulation of serotonin levels worsen memory performance. Other cognitive functions such as cognitive flexibility and attention are possibly also modulated by serotonin (Schmitt et al., 2006). 
Particularly, sustained attention, often called vigilance, is one aspect of the general construct of attention that is associated with serotonergic functioning (Schmitt et al., 2002). Single and repeated doses of SSRIs have been shown to reduce sustained attention in healthy volunteers in a number of studies using the Mackworth Clock Test paradigm (Ramaekers et al., 1995; O'Hanlon et al., 1998; Schmitt et al., 2002; Riedel et al., 2005). While performing the Mackworth Clock Test, participants have to sustain their attention for 45 min while monitoring a circular arrangement of sequentially illuminating dots. A button press is required when a rare event occurs (signal detection) (Mackworth, 1950). As time passes, it becomes more difficult to sustain attention and more misses occur. This is called the vigilance decrement (Teichner, 1974).

Antidepressants are suitable means for challenging the serotonergic system while measuring cognitive functions. Moreover, combining (psycho)pharmacological studies with functional magnetic resonance imaging (fMRI) might give more insight into the underlying neuroanatomical substrates of task performance and changes in functioning of these brain areas associated with cognitive performance. Previous pharmaco-fMRI studies for establishing the association between serotonin and cognition have used several antidepressants. For instance, one study used the noradrenergic and specific serotonergic antidepressant (NaSSa) mirtazapine to examine the effects of serotonin on behavioral inhibition in a parallel group design. The results showed a modulatory role for serotonin of brain responses in a Go/No-Go and a Reward/No-Reward task in various brain areas including orbitofrontal cortex and parietal cortex (Vollm et al., 2006). Unfortunately, mirtazapine has additional noradrenergic and histaminergic affinity, which can influence the results on the behavior level as well as on the neuroanatomic level. Ideally, a more selective serotonergic antidepressant is required. Another study used the SSRI citalopram in a withinsubject fMRI design and demonstrated effects of serotonin on brain areas involved in several neuropsychological tasks, despite little behavioral changes due to a ceiling effect (Del Ben et al., 2005). Another previous functional MRI study also demonstrated that a single dose of citalopram changes the serotonergic system (McKie et al., 2005). A very recent study demonstrated a role for serotonin in modulating amygdala activation to aversive faces, tested in an fMRI-setting after citalopram administration (Anderson et al., 2007). No prior pharmaco-fMRI studies have yet been undertaken to assess the effects of serotonin on sustained attention.
The aim of the present study was to define the brain regions that are involved in performance during the Mackworth Clock Test. In addition, the effects of increased serotonin levels in healthy human volunteers were assessed on sustained attention and on brain areas underlying sustained attention. Serotonin stimulation was obtained by blocking serotonin reuptake through administration of the most selective SSRI, escitalopram. It was expected that acutely increased serotonin levels would impair sustained attention performance measured by the Mackworth Clock Test. In addition, this impaired performance was expected to be reflected in activation changes in the brain areas that underlie sustained attention. Previous studies using sustained attention tasks and fMRI showed involvement of the right parietal and frontal brain areas (Lewin et al., 1996; Coull et al., 1998; O'Conner et al., 2004). It was expected that the same brain areas would be involved while performing the Mackworth Clock Test.

\section{EXPERIMENT AND METHODS}

\section{Subjects}

Ten healthy volunteers $(5+, 5 \preccurlyeq)$, mean age (s.e.) 26.3 (2.46) were recruited. All participants underwent a screening procedure, which consisted of a telephone interview, health questionnaire, 12-lead electrocardiogram, laboratory testing (hematology and blood chemistry, urinalysis, drug- and pregnancy screening) and a routine medical examination. Volunteers were included when they were 21 to 45 years of age, healthy, had a normal static binocular acuity (corrected or uncorrected), a body mass index between 19 and 30, and were willing to sign an informed consent. Excluded were those volunteers who suffered from, or had a history of cardiac, hepatic, renal, pulmonary, neurological, gastrointestinal, hematological, or psychiatric illness. History of psychiatric illness or current psychiatric illness was assessed by the health questionnaire which was approved by a medical doctor. Other exclusion criteria were excessive drinking $(>20$ glasses of alcohol containing beverages a week), pregnancy or lactation, menstrual disorder, use of medication other than oral contraceptives, smoking tobacco, or use of illicit drugs, and any sensory or motor deficits which could reasonably be expected to affect test performance. Those volunteers who had a first-degree relative with a psychiatric disorder or a history of a psychiatric disorder were also excluded. The study was approved by the standing medical ethics committee of Maastricht University and the Maastricht Academic 
Hospital's Board of Directors. It was carried out in accordance with the World Medical Association's Declaration of Helsinki (Edinburgh, 2000). Written informed consent was obtained from each volunteer prior to participation to the study.

\section{Design and treatment}

The study was conducted according to a double-blind, placebo controlled, two-way crossover design. Complete balancing of the treatments led to two treatment orders that were randomly assigned to the participants. Treatments consisted of escitalopram $(20 \mathrm{mg})$ and placebo administered at two different test days separated by a wash-out period of at least 7 days. The treatments were randomly assigned resulting in a balanced treatment design.

\section{Testing procedure}

Participants underwent a short training session of the Mackworth Clock Test on the day of the medical examination in order to minimize learning effects. On the two separate test days, participants arrived at 9.00 a.m. at the laboratory, filled out an informed consent concerning scanning procedures, received a standard breakfast, and completed a sleep quality questionnaire. They received the treatment capsule containing either escitalopram or placebo at 9.30 a.m. Participants were then seated for the next few hours in a secluded waiting room in order to wait for escitalopram to reach the maximum concentration in blood $\left(\mathrm{C}_{\max }\right)$. At noon participants received a standard light lunch. Mood assessments were conducted at 13.00 p.m. followed by an anatomical scan. Scanning and testing took place at 13.30 p.m., that is, $4 \mathrm{~h}$ after drug intake, till 14.15 p.m. Both test days were identical in design. Participants were not allowed to consume alcohol $24 \mathrm{~h}$ prior to testing and caffeine-containing beverages $4 \mathrm{~h}$ prior to the start of the test day.

\section{Subjective measurements}

Subjects filled out the Groninger Sleep Quality Scale (Mulder-Hajonides van der Meulen, 1981) on each test day to assess sleep quality during the preceding night. The total score consisted of 14 yes/no questions to score the number of sleep complaints (ranging from good sleep (score 0) to worst possible sleep (score 14)). In addition, specific questions on time needed to fall asleep, number of awakenings during the night and sleep duration in hours were included. The Bond and Lader Questionnaire was also assessed using different scales for alertness, contentedness and calmness (Bond and Lader, 1974).

\section{FMRI data acquisition}

A 3T Siemens Allegra MR scanner, situated at the Faculty of Psychology (University Maastricht, The Netherlands) was used for the anatomical and functional measurements. A T1-weighted anatomical scan was acquired for each subject using a 3-D Modified Driven Equilibrium Fourier Transform (MDEFT) sequence with an isotropic spatial resolution of $1 \mathrm{~mm}$. During task performance 896 whole-brain volumes of $\mathrm{T} 2{ }^{*}$-weighted functional measurements were acquired, each comprising 32 slices (slice thickness $3.5 \mathrm{~mm}$; no slice gap; flip angle $90^{\circ}$ ) using a blood oxygenation level dependent (BOLD) measurement and echo planar image (EPI) pulse sequence (TR: $2 \mathrm{~s}$; TE: $30 \mathrm{~ms}$; resolution: $3.5 \times 3.5 \times 3.5 \mathrm{~mm}^{3}$, matrix size $64 \times 64$ ) and interleaved slice sampling. Stimulus presentation and scanning were synchronized at the beginning of the task.

\section{Sustained attention-Mackworth Clock Test}

Participants were scanned on two occasions (placebo condition and escitalopram condition). FMRI scans were obtained while subjects performed the Mackworth Clock Test for $30 \mathrm{~min}$. Participants laid supine in the scanner with the head fixated with foam pads. Headphone and earplugs were provided. Participants looked at the projection of a computer screen displaying a circular arrangement of 60 gray dots, via a mirror in the head volume coil. The dots were briefly illuminated in clockwise rotation at a rate of one per $500 \mathrm{~ms}$, moving $6^{\circ}$ from dot to dot. Volunteers were instructed that occasionally the dot would move $12^{\circ}$. This "skipping of one of the dots" was the signal participants had to detect throughout the task by pressing a response button as fast as possible with the right index finger. A response within $3 \mathrm{~s}$ of the signal was registered as a correct detection. A total of 20 signals were randomly presented with 10 per $15 \mathrm{~min}$ period. Behavioral measures were total correct detections (hits) and corresponding reaction times. For objectives of a different study a resting condition (fixation) was included prior to as well as proceeding to the task block. These additional time points were modeled as covariates in the current study.

\section{Statistical analyses}

Behavioral data were analyzed by means of a repeated measures general linear model (GLM) analysis (SPSS

Hum. Psychopharmacol Clin Exp 2008; 23: 221-230. 
11.5) with Treatment ( 2 levels) and Time on task ( 2 levels) as the main factors. The alpha criterion significance level was set at $p=0.05$.

Preprocessing of the functional images was done using BrainVoyager QX version 1.6 (www.brainvoyager.com), and contained slice scan correction, 3-D motion correction (trilinear interpolation) and linear trend removal and high pass temporal filtering (cutoff $=5$ cycles per time course), no spatial smooting. Individual anatomical datasets were spatially normalized to a standardized 3-D space (Talairach and Tournoux, 1988). Individual scans were realigned using the first scan as a reference and coregistered and normalized to the anatomical data, and resampled to a voxel size of $3 \times 3 \times 3 \mathrm{~mm}^{3}$.

Analysis of the brain activations was performed using a whole-brain, fixed effects ANCOVA that included 12 predictors based on the task design. A protocol specific for each subject and each condition entailed the predictors. These predictors included correct detections, misses, false alarms, task block, time before correct detections, fixation (resting condition), and 6 motion correction preprocessing parameters. The predictor correct response (corresponding to two time scans or volumes) was used as a main measure for sustained attention as previous studies showed an effect of increased serotonin levels on this variable (Ramaekers et al., 1995; O'Hanlon et al., 1998; Schmitt et al., 2002; Riedel et al., 2005). The implication was that as a participant responds to the event (signal detection), it is also sustaining attention. A maximum of 20 correct detections per subject per condition were included in the analysis.

Results were color-coded and superimposed onto a standardized template of a single brain. Main task effects of placebo were visualized using a $p$ (bonf) $<0.01$ corrected, and a cluster threshold of $>100$ voxels. Activation corresponding to the main measure (correct responses) is relative to baseline activity meaning all other (mean) activity. The differential effect of escitalopram was analyzed using whole-brain analyses within the placebo-escitalopram contrast on the correct responses of the task using a $q$ (FDR) $<0.001$ (Genovese et al., 2002) (which corresponded to $p<0.000008$, uncorrected) and a cluster threshold of $>50$ voxels. Activation within the contrast is the activation corresponding to the main measure after escitalopram administration relative to the activation corresponding to the main measure after placebo administration. Subsequent event-related averaging on the significant voxels of the ROI of the cluster time courses, corresponding to the correct response trials, was performed. Events were selected through the protocols which were based on the subjects' performance and an average was calculated per condition (escitalopram or placebo).

\section{RESULTS}

\section{Missing data}

In total, 12 participants were included of which two ended their participation due to claustrophobic reactions in the fMRI scanner. Ten participants completed the study, there were no missing data. Escitalopram was well tolerated in all subjects.

\section{Behavioral data}

Means and standard errors (s.e.) of the sustained attention task performance are shown in Table 1.

Treatment did not significantly affect correct detections or reaction time $\left(F_{1,9}=0.91, p=0.366\right)$. There was a trend for a Time on task effect for correct detections $\left(F_{1,9}=3.41, p=0.098\right)$ and a significant Time on task effect for reaction time $\left(F_{1,9}=9.61\right.$, $p=0.013$ ), which indicates an overall tendency for a vigilance decrement during the $30 \mathrm{~min}$ performance. There was no Treatment by Time on task interaction effect.

\section{Subjective measurements}

Mean (s.e.) of subjective evaluations are shown in Table 1. The outcome measures of the Groninger Sleep Quality Scale were not different for the two treatments. Treatment did significantly affect the alertness ratings $\left(F_{1,9}=21.5, p=0.001\right)$ but not the contentedness or calmness ratings. Escitalopram reduced alertness as compared to placebo.

Table 1. Mean (s.e.) outcome variables of the Mackworth Clock Test and the Bond and Lader Questionnaire

\begin{tabular}{lrr}
\hline Treatment $N=10$ & Escitalopram & Placebo \\
\hline Mackworth Clock Test & & \\
$\quad$ Total correct responses & $15.8(1.25)$ & $15.0(1.69)$ \\
Total reaction time (ms) & $629(32.4)$ & $662(38.3)$ \\
Correct responses 0-15 min & $8.4(0.50)$ & $7.9(0.92)$ \\
Reaction time 0-15 min (ms) & $589(25.4)$ & $635(36.5)$ \\
Correct responses 15-30 min & $7.4(0.82)$ & $7.1(0.91)$ \\
$\quad$ Reaction time 15-30 min & $664(43.2)$ & $680(42.3)$ \\
Bond and Lader Questionnaire & & \\
$\quad$ Alertness & $67.0(6.37)^{\mathrm{a}}$ & $81.4(3.96)$ \\
Contentedness & $79.0(4.41)$ & $83.4(4.05)$ \\
Calmness & $79.3(4.28)$ & $80.7(5.21)$ \\
\hline${ }^{a} p=0.001$. & &
\end{tabular}

Hum. Psychopharmacol Clin Exp 2008; 23: 221-230. 


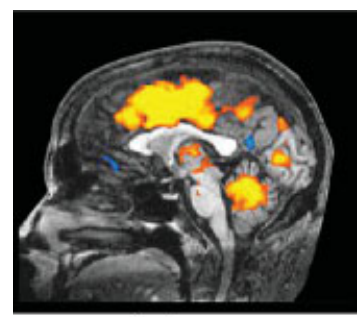

(a)

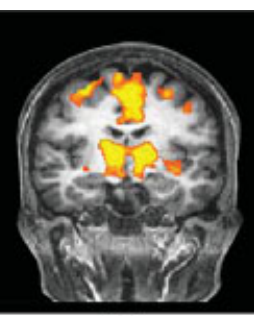

(b)

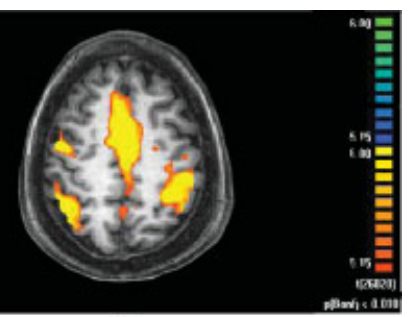

(c)

Figure 1. Main task effect of the Mackworth Clock Test (correct detections) in the placebo condition, increased and decreased activations are both presented at a $p$ (bonf) $<0.01$ and a cluster threshold of $>100$ voxels. (a) Sagittal plane; (b) coronal plane; (c) transaxial plane

\section{Functional MRI during task performance}

Figure 1 shows significantly activated brain areas in the placebo condition during the Mackworth Clock Test: activation corresponding to the correct responses relative to baseline (all other) task performance. The main effect of task showed increased activation of motor areas including the left post central gyrus, the right precentral gyrus, the middle cingulate gyrus, and the supplemental motor area. In addition there was increased activation in brain areas associated with an attentional network including the right inferior parietal gyrus, the right angular gyrus, the insula, the thalamus, and the caudate nucleus. Other areas which showed increased activation were the middle frontal gyrus, the right middle temporal gyrus, the parietal-occipital fissure, the precuneus, and the vermis. Decreased activation was seen in the posterior and anterior cingulate gyrus.

Figure 2 shows significantly activated brain areas after a contrast between escitalopram and placebo two conditions with corresponding event-related averaging plots. Comparing activation corresponding to the correct responses in the escitalopram condition to activation corresponding to the correct responses in the placebo condition resulted in decreased activation of the left supplementary motor area, parts of the thalamus, the left caudate nucleus, the left precentral sulcus, the right middle frontal gyrus, the left inferior frontal gyrus, and the left superior frontal gyrus. In addition, after escitalopram administration there was increased activation in the right superior temporal

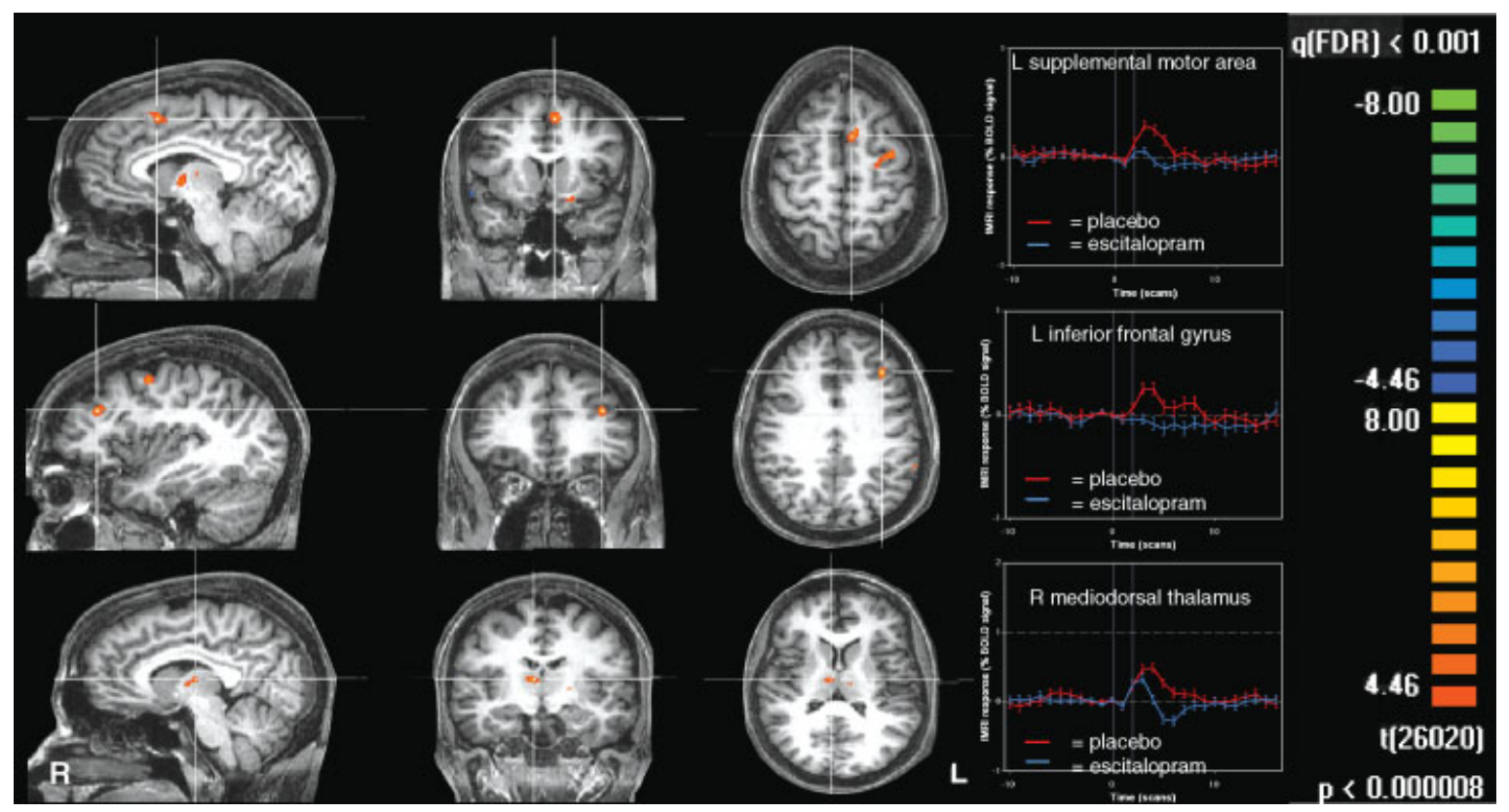

Figure 2. Decreased activation after the placebo-escitalopram contrast at $q$ (FDR) $<0.001$ and a cluster threshold of $>50$ voxels 
Table 2. Areas in which voxels were activated corresponding to correct detections of the Mackworth Clock Test

\begin{tabular}{|c|c|c|c|c|c|c|c|c|c|c|c|c|}
\hline \multirow[b]{2}{*}{ Region } & \multirow[b]{2}{*}{$\begin{array}{l}\text { Left/ } \\
\text { Right }\end{array}$} & \multicolumn{5}{|c|}{$\begin{array}{l}\text { Main effect (placebo) } \\
\text { Talairach coordinates }\end{array}$} & \multirow[b]{2}{*}{$\begin{array}{l}\text { Left/ } \\
\text { Right }\end{array}$} & \multicolumn{5}{|c|}{$\begin{array}{l}\text { Different activation after } \\
\text { escitalopram administration } \\
\text { Talairach coordinates }\end{array}$} \\
\hline & & $X$ & $Y$ & $Z$ & $\begin{array}{l}\text { Number } \\
\text { of voxels }\end{array}$ & $\begin{array}{l}\text { Mean } \\
t \text {-value }\end{array}$ & & $X$ & $Y$ & $Z$ & $\begin{array}{l}\text { Number } \\
\text { of voxels }\end{array}$ & $\begin{array}{c}\text { Mean } \\
t \text {-value }\end{array}$ \\
\hline Postcentral gyrus/motor cortex ${ }^{a}$ & $\mathrm{~L}$ & -30 & -30 & 50 & 945 & 7.725 & & & & & & \\
\hline Middle cingulate gyrus ${ }^{\mathrm{a}}$ & $\mathrm{L} / \mathrm{R}$ & 1 & 3 & 36 & 1331 & 10.248 & & & & & & \\
\hline Supplementary motor area ${ }^{\text {ad }}$ & $\mathrm{L} / \mathrm{R}$ & 2 & 12 & 51 & 1321 & 9.043 & $\mathrm{~L}$ & -6 & 11 & 48 & 333 & -4.972 \\
\hline Inferior parietal gyrus ${ }^{\mathrm{a}}$ & $\mathrm{R}$ & 40 & -47 & 42 & 1045 & 8.771 & & & & & & \\
\hline \multirow[t]{2}{*}{ Precentral gyrus ${ }^{\mathrm{a}}$} & $\mathrm{R}$ & 41 & -6 & 41 & 963 & 7.494 & & & & & & \\
\hline & $\mathrm{R}$ & 46 & 3 & 24 & 1274 & 7.946 & & & & & & \\
\hline Angular gyrus ${ }^{\mathrm{a}}$ & $\mathrm{R}$ & 49 & -43 & 31 & 1211 & 9.330 & & & & & & \\
\hline Middle temporal gyrus ${ }^{\mathrm{a}}$ & $\mathrm{R}$ & 53 & -43 & 9 & 1160 & 8.336 & & & & & & \\
\hline Insula $^{\mathrm{a}}$ & $\mathrm{L} / \mathrm{R}$ & 35 & 18 & 7 & 1331 & 11.139 & & & & & & \\
\hline Thalamus $^{\mathrm{a}}$ & $\mathrm{L} / \mathrm{R}$ & 9 & -16 & 10 & 1070 & 8.015 & & & & & & \\
\hline Ventral nucleus left ${ }^{\mathrm{d}}$ & & & & & & & $\mathrm{L}$ & -8 & -18 & 9 & 54 & -4.649 \\
\hline Mediodorsal nucleus left ${ }^{\mathrm{d}}$ & & & & & & & $\mathrm{L}$ & -5 & -7 & 9 & 209 & -4.991 \\
\hline Mediodorsal nucleus right ${ }^{\mathrm{d}}$ & & & & & & & $\mathrm{R}$ & 7 & -13 & 11 & 176 & -4.847 \\
\hline Anterior nucleus ${ }^{\mathrm{d}}$ & & & & & & & $\mathrm{L} / \mathrm{R}$ & 0 & -5 & 7 & 372 & -5.021 \\
\hline Caudate nucleus $^{\text {ad }}$ & $\mathrm{L} / \mathrm{R}$ & 9 & 5 & 9 & 1133 & 7.247 & $\mathrm{~L}$ & -13 & 4 & 14 & 262 & -4.796 \\
\hline Middle frontal gyrus ${ }^{\mathrm{a}}$ & $\mathrm{L} / \mathrm{R}$ & 37 & 37 & 24 & 835 & 6.064 & & & & & & \\
\hline Parietal-occipital fissure ${ }^{a}$ & $\mathrm{~L} / \mathrm{R}$ & 10 & -70 & 28 & 735 & 6.349 & & & & & & \\
\hline Precuneus $^{\mathrm{a}}$ & $\mathrm{L} / \mathrm{R}$ & 1 & -53 & 35 & 645 & 6.234 & & & & & & \\
\hline Vermis $^{\mathrm{a}}$ & $\mathrm{L} / \mathrm{R}$ & 2 & -53 & -19 & 1317 & 8.565 & & & & & & \\
\hline Posterior cingulate gyrus ${ }^{\mathrm{b}}$ & $\mathrm{L} / \mathrm{R}$ & -3 & -54 & 17 & 652 & -6.055 & & & & & & \\
\hline Anterior cingulate gyrus ${ }^{\mathrm{b}}$ & $\mathrm{L} / \mathrm{R}$ & -3 & 31 & -7 & 157 & -5.455 & & & & & & \\
\hline Precentral sulcus ${ }^{\mathrm{d}}$ & & & & & & & $\mathrm{L}$ & -24 & -8 & 51 & 299 & -4.975 \\
\hline Middle frontal gyrus ${ }^{\mathrm{d}}$ & & & & & & & $\mathrm{R}$ & 32 & 16 & 43 & 79 & -4.824 \\
\hline Inferior frontal gyrus & & & & & & & $\mathrm{L}$ & -34 & 31 & 28 & 183 & -5.072 \\
\hline Superior frontal gyrus ${ }^{\mathrm{d}}$ & & & & & & & $\mathrm{L}$ & -27 & 53 & 15 & 67 & -4.731 \\
\hline Superior temporal gyrus ${ }^{\mathrm{c}}$ & & & & & & & $\mathrm{R}$ & 53 & 4 & 4 & 76 & 4.763 \\
\hline Lateral fissure ${ }^{\mathrm{c}}$ & & & & & & & $\mathrm{R}$ & 61 & -19 & 15 & 77 & 4.856 \\
\hline
\end{tabular}

${ }^{\mathrm{a}}$ Increased activation.

${ }^{\mathrm{b}}$ Decreased activation.

${ }^{\mathrm{c}}$ Significant increase of activation compared to placebo.

${ }^{\mathrm{d}}$ Significant decrease of activation compared to placebo.

gyrus and the right lateral fissure. The event-related plots of the specific brain areas in the contrast between the two conditions showed less or no response (BOLD signal) after escitalopram administration. In Table 2, significantly activated brain areas during Mackworth Clock Test performance are presented in the placebo condition and after a contrast between the two conditions (placebo-escitalopram) including mean $t$-value and number of voxels. Figure 3 shows the event-related averaging plot of the primary motor cortex, which shows no difference between the two conditions.

\section{DISCUSSION}

The present study examined the effects of increased serotonin levels on sustained attention and underlying

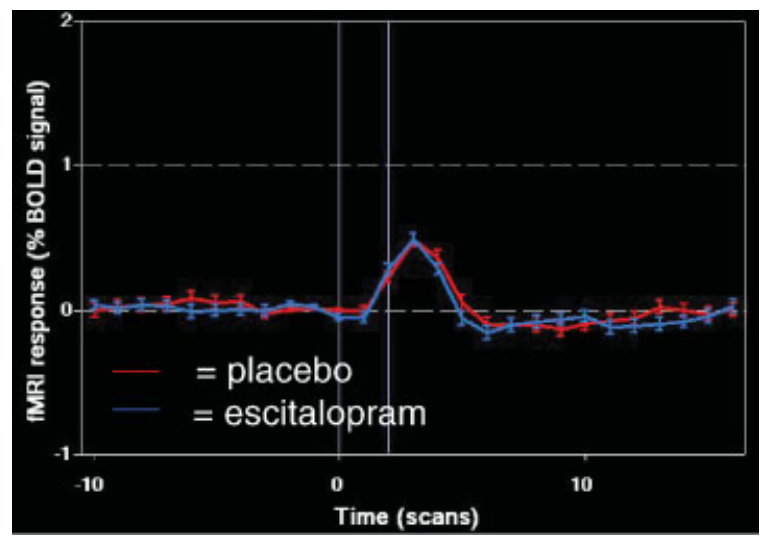

Figure 3. Event-related plot in the primary motor cortex which shows no difference between escitalopram and placebo administration 
brain activation. Similar to previous studies that measured sustained attention (Lewin et al., 1996; Coull et al., 1998; O'Conner et al., 2004) the current study showed activation of right dorsal and prefrontal areas. The brain areas of the present study involved in sustained attention show some remarkable overlap with brain areas associated with visual attention (Corbetta et al., 2002). In addition, escitalopram and consequently the neurotransmitter serotonin modulated activity of several brain areas including the thalamus and prefrontal areas during a sustained attention task, although no effect was found on behavioral measurements of sustained attention.

Performance of the Mackworth Clock Test in the placebo condition showed increased activation was found in the right inferior parietal gyrus, the right angular gyrus, the right precentral gyrus, the insula bilateral, the thalamus bilateral, and the bilateral middle frontal gyrus. These areas and particularly right parietal and prefrontal areas have been associated with sustained attention in previous research with fMRI (Cabeza and Nyberg, 2000; Sturm and Willmes, 2001) and Positron emission tomography (PET) (Mottaghy et al., 2006). Using the rapid visual information (RIVP) task to assess networks of sustained attention, Lawrence et al. (2003) demonstrated a network comprising frontal and parietal cortical areas and the thalamus and caudate nucleus, which is very comparable to the set of active brain areas found in the present study (Lawrence et al., 2003). Coull (1998) suggests that two different networks are involved in attention and arousal and interact with each other: a cortical network including the right frontal and inferior parietal cortex, which is associated with attention and a subcortical network including the thalamus, striatum, and the anterior cingulate, which is associated with arousal (Coull, 1998). Adequate levels of both arousal and attention are necessary to achieve good sustained attention performance (Coull, 1998). Other areas with increased activation in the present study were areas associated with the response by a button press including the left postcentral gyrus/ motor cortex and the supplemental motor area. Activation of the parietal-occipital fissure is probably related to the seeing of the signal in the Mackworth Clock Test, as this area has been previously associated with the perception of visual motion (Richer et al., 1991).

After escitalopram administration, differences in activation were seen in several brain areas. Decreased activation was seen in parts of the basal ganglia, including the ventral lateral nucleus of the left thalamus, the mediodorsal nucleus of thalamus bilateral, and the left caudate nucleus. In addition, the left superior precentral sulcus, the left superior frontal gyrus, and the right middle frontal gyrus also showed decreased activation after acutely elevated serotonin levels. The event-related plots of these areas also showed lower amplitude of activity and/or a post-event dip in activation for the escitalopram administration condition in the above-mentioned areas. These decreased activations did not appear in the motor cortex, there were no differences between the two conditions in the primary motor cortex and also the event-related plot of the primary motor cortex showed an equal BOLD response after escitalopram and placebo. This suggests that the observed effects may be related to cognitive effects, possibly sustained attention.

Several nuclei of the thalamus including the ventrolateral and mediodorsal nuclei, in which decreased activity is found after escitalopram administration in the present study, are involved in mediating the interaction between attention and arousal in humans (Portas et al., 1998). The findings of the present study suggest that increments in serotonin levels may impair sustained attention through influencing the interaction between the cortical and subcortical networks involved in arousal and attention described previously by Coull et al. (1998). A candidate mechanism of the influence of serotonin on selective changes in brain activity may be through a serotonin-dopamine interaction mechanism. The basal ganglia (including the thalamus and the caudate nucleus) are often associated with the neurotransmitter dopamine (Garnett et al., 1983) and it has previously been proposed that serotonin has a general inhibitory effect on dopamine release (Soubrie, 1986; Spoont, 1992). Particularly serotonin projections from the raphe nucleus have an inhibitory influence over the mesocortical dopamine system and forebrain, which are involved in cognition (Kapur and Remington, 1996). It could be suggested that serotonin may impair sustained attention through inhibiting dopamine in the thalamus and the caudate nucleus. Consequently, a decrease in dopamine may lead to less activation of the mesocortical dopamine projections to the prefrontal cortex (Robbins, 1997). The results from the present study support this statement by showing decreased activity in the thalamus as well as in (pre)frontal areas after serotonin stimulation. In humans and in primates, connections between the mediodorsal nuclei of the thalamus and the prefrontal cortex are well demonstrated (Siwek and Pandya, 1991; Behrens et al., 2003) and these connections are involved in top-down modulation of attention ( $\mathrm{La}$ Berge, 1995). 
The present study did not show an effect of increased serotonin stimulation on behavioral measurements of attention. However, other studies did find an impairing effect of serotonin on sustained attention measured by the Mackworth Clock Test (Ramaekers et al., 1995; O'Hanlon et al., 1998; Schmitt et al., 2002; Riedel et al., 2005). The differences between the previous studies and the present study are probably due to a small sample size and a small effect size. In addition, in the present fMRI study, the task only lasted $30 \mathrm{~min}$ whereas it lasted $45 \mathrm{~min}$ in performance studies. Possibly, the task duration was too short to pick up any significant differences between the treatment conditions, which is supported by our finding of a non-significant trend of a vigilance decrement. Escitalopram did decrease alertness subjectively but this was not reflected in behavioral measures of sustained attention. In addition, the entire procedure of conducting the task in the scanner may have influenced performance in that both treatments affect sustained attention in a comparable way. The number of correct detections after $30 \mathrm{~min}$ in the placebo condition in other (not-fMRI) studies is around 17.4 (s.e. \pm 2.0 ) (Ramaekers et al., 1995; Wingen et al., 2006a). In the present study the number of correct detections in the placebo condition is certainly lower, 15.0 (s.e. \pm 1.8 ).

An important issue is the influence of drug administration on general blood flow. In fMRI, activations measured are an indirect reflection of neural activity but a direct reflection of the difference between the magnetic properties of oxygenated and deoxygenated hemoglobin or BOLD response. Theoretically, it is possible that serotonin influenced blood flow or BOLD changes in the present study. However, activations seen in the current study are task dependent and specific. This is in line with a previous study using intravenous administration of the SSRI citalopram that demonstrated that citalopram is a good tool to use in pharmacoMRI studies to manipulate the serotonergic system (McKie et al., 2005). Furthermore, the present study showed increased activations as well as decreased activations of BOLD response after increased serotonin levels in the same task manipulation. Activations in opposite direction are not possible in the context of a general effect on blood flow. Finally, SSRIs in general have few cerebrovascular effects (Ramasubbu, 2004) and particularly $20 \mathrm{mg}$ of the parent compound of escitalopram (citalopram) did not alter heart rate in healthy males (Seifritz et al., 1996). Therefore, it is unlikely that general effects on the BOLD response caused by escitalopram influenced the results.
Presently, there are some limitations in the analysis of the fMRI data and the study design. Unfortunately, the small sample only permitted a fixed effect analysis of the fMRI data. In a future study with a bigger sample, random effect analysis would be preferable given the within-subject design. Furthermore, the analysis is driven by a model based on the task design which includes several predictors. The Mackworth Clock paradigm was used for the present study to be comparative to previous studies on sustained attention and SSRIs. The predictor "correct responses" and the brain activation corresponding to the correct responses relative to baseline task performance were used as a main measure for sustained attention. Perhaps, another model with other predictors may even better reflect a measure of sustained attention. For future studies it would be very interesting to use a data-driven method such as independent component analysis (ICA) (McKeown and Sejnowski, 1998) to indicate different components or functional networks related to sustained attention. The decreased activity demonstrated in the anterior and posterior cingulate cortex in the present study is a remarkable finding to further examine with ICA as these areas seem to be involved in a certain network concerning resting and are shown to decrease when the cognitive demand of a certain task increases (Raichle et al., 2001). Furthermore, the use of this method would allow us to better attribute the influence of increased serotonin on sustained attention to a certain neural network.

To conclude, the current study implies that serotonin stimulation may impair sustained attention through modulation of selective brain areas including (pre)frontal areas and parts of the basal ganglia, which are possibly involved in a subcortical network for sustained attention. The results presented have opened doors for future imaging studies on serotonin and sustained attention. More research is needed to draw stronger conclusions.

\section{ACKNOWLEDGEMENTS}

The authors are thankful to Sven J.C. Gijsen for his assistance in scanning procedures and data collection and medical doctor Cees J. van Leeuwen for his medical assistance.

\section{REFERENCES}

Anderson IA, Del-Ben CM, McKie S, et al. 2007. Citalopram modulation of neuronal responses to aversive face emotions: a functional MRI study. Neuroreport 18: 1351-1355.

Hum. Psychopharmacol Clin Exp 2008; 23: 221-230. 
Austin MP, Mitchell P, Goodwin GM. 2001. Cognitive deficits in depression: possible implications for functional neuropathology. Br J Psychiatry 178: 200-206.

Behrens TE, Johansen Berg H, Woolrich MW, et al. 2003. Noninvasive mapping of connections between human thalamus and cortex using diffusion imaging. Nat Neurosci 6(7): 750-757.

Bond A, Lader M. 1974. The use of analogue scales in rating subjective feelings. Br J Med Psychol 47(3): 211-218.

Cabeza R, Nyberg L. 2000. Imaging cognition II: an empirical review of 275 PET and fMRI studies. J Cogn Neurosci 12(1): $1-47$.

Corbetta M, Kincade JM, Shulman GL. 2002. Neural systems for visual orienting and their relationships to spatial working memory. J Cogn Neurosci 14(3): 508-523.

Coull JT. 1998. Neural correlates of attention and arousal: insights from electrophysiology, functional neuroimaging and psychopharmacology. Prog Neurobiol 55(4): 343-361.

Coull JT, Frackowiak RS, Frith CD. 1998. Monitoring for target objects: activation of right frontal and parietal cortices with increasing time on task. Neuropsychologia 36(12): 1325-1334.

Del Ben CM, Deakin JF, McKie S, et al. 2005. The effect of citalopram pretreatment on neuronal responses to neuropsychological tasks in normal volunteers: an FMRI study. Neuropsychopharmacology 30(9): 1724-1734.

Doraiswamy PM, Krishnan KR, Oxman T, et al. 2003. Does antidepressant therapy improve cognition in elderly depressed patients? J Gerontol 58(12): M1137-M1144.

Elliott R, Baker SC, Rogers RD, et al. 1997. Prefrontal dysfunction in depressed patients performing a complex planning task: a study using positron emission tomography. Psychol Med 27(4): 931-942.

Garnett ES, Firnau G, Nahmias C. 1983. Dopamine visualized in the basal ganglia of living man. Nature 305(5930): 137-138.

Genovese CR, Lazar NA, Nichols T. 2002. Thresholding of statistical maps in functional neuroimaging using the false discovery rate. NeuroImage 15(4): 870-878.

Kapur S, Remington G. 1996. Serotonin-dopamine interaction and its relevance to schizophrenia. Am J Psychiatry 153(4): 466-476.

Koetsier GC, Volkers AC, Tulen JH, Passchier J, van den Broek WW, Bruijn JA. 2002. CPT performance in major depressive disorder before and after treatment with imipramine or fluvoxamine. J Psychiatr Res 36(6): 391-397.

La Berge D. 1995. Attentional Processing. Harvard University Press: Cambridge.

Landro NI, Stiles TC, Sletvold H. 2001. Neuropsychological function in nonpsychotic unipolar major depression. Neuropsychiatry Neuropsychol Behav Neurol 14(4): 233-240.

Lawrence NS, Ross TJ, Hoffmann R, Garavan H, Stein EA. 2003. Multiple neuronal networks mediate sustained attention. J Cogn Neurosci 15(7): 1028-1038.

Lewin JS, Friedman L, Wu D, et al. 1996. Cortical localization of human sustained attention: detection with functional MR using a visual vigilance paradigm. J Comput Assist Tomogr 20(5): 695-701.

Mackworth NH. 1950. Researches on the measurement of human performance. In Selected Papers on Human Factors in the Design and Use of Control Systems, Sinaiko HW (ed). Dover: New York; 174-331.

McKeown MJ, Sejnowski TJ. 1998. Independent component analysis of fMRI data: examining the assumptions. Hum Brain Mapp 6(5-6): 368-372.

McKie S, Del Ben C, Elliott R, et al. 2005. Neuronal effects of acute citalopram detected by pharmacoMRI. Psychopharmacology 180(4): 680-686.
Meeter M, Talamini L, Schmitt JA, Riedel WJ. 2006. Effects of 5-HT on memory and the hippocampus: model and data. Neuropsychopharmacology 31(4): 712-720.

Meltzer H. 1989. Serotonergic dysfunction in depression. $\mathrm{Br} J$ Psychiatry 8 (suppl): 25-31.

Mottaghy FM, Willmes K, Horwitz B, Muller HW, Krause BJ, Sturm W. 2006. Systems level modeling of a neuronal network subserving intrinsic alertness. NeuroImage 29(1): 225-233.

Mulder-Hajonides van der Meulen WREH. 1981. Measurement of subjective sleep quality. In Proceedings of the International European Sleep Congress. Elsevier: Amsterdam.

O'Conner C, Manly T, Robertson IH, Hevenor SJ, Levine B. 2004. An fMRI study of sustained attention with endogenous and exogenous engagement. Brain Cogn 54: 133-176.

O'Hanlon J, Robbe HWJ, Vermeeren A, VanLeeuwen C, Danjou PE. 1998. Venlafaxine's effects on healthy volunteers' driving, psychomotor, and vigilance performance during 15-day fixed and incremental dosing regimens. J Clin Psychopharmacol 18(3): 212-221.

Portas CM, Rees G, Howseman AM, Josephs O, Turner R, Frith CD. 1998. A specific role for the thalamus in mediating the interaction of attention and arousal in humans. J Neurosci 18(21): 8979-8989.

Raichle ME, MacLeod AM, Snyder AZ, Powers WJ, Gusnard DA, Shulman GL. 2001. A default mode of brain function. Proc Natl Acad Sci U S A 98(2): 676-682.

Ramaekers JG, Muntjewerff ND, O'Hanlon JF. 1995. A comparative study of acute and subchronic effects of dothiepin, fluoxetine and placebo on psychomotor and actual driving performance. $\mathrm{Br} J$ Pharmacol 39(4): 397-404.

Ramasubbu R. 2004. Cerebrovascular effects of selective serotonin reuptake inhibitors: a systematic review. J Clin Psychiatry 65(12): 1642-1653.

Richer F, Martinez M, Cohen H, Saint Hilaire JM. 1991. Visual motion perception from stimulation of the human medial parieto-occipital cortex. Exp Brain Res 87(3): 649-652.

Riedel WJ, Klaassen T, Deutz NE, van Someren A, van Praag HM. 1999a. Tryptophan depletion in normal volunteers produces selective impairment in memory consolidation. Psychopharmacology (Berl) 141(4): 362-369.

Riedel WJ, Schoenmakers E, Vermeeren A, O’Hanlon JF. 1999b. The influence of trazodone treatment on cognitive functions in outpatients with major depressive disorder. Hum Psychopharmacol: Clin Exp 14(7): 499-508.

Riedel WJ, Klaassen T, Griez E, Honig A, Menheere PP, van Praag HM. 2002. Dissociable hormonal, cognitive and mood responses to neuroendocrine challenge: evidence for receptor-specific serotonergic dysregulation in depressed mood. Neuropsychopharmacology 26(3): 358-367.

Riedel WJ, Eikmans K, Heldens A, Schmitt JA. 2005. Specific serotonergic reuptake inhibition impairs vigilance performance acutely and after subchronic treatment. J Psychopharmacol 19(1): $12-20$.

Robbins TW. 1997. Arousal systems and attentional processes. Biol Psychol 45(1-3): 57-71.

Schmitt JAJ, Ramaekers JG, Kruizinga MJ, van Boxtel MP, Vuurman EF, Riedel WJ. 2002. Additional dopamine reuptake inhibition attenuates vigilance impairment induced by serotonin reuptake inhibition in man. J Psychopharmacol 16(3): 207214.

Schmitt JAJ, Wingen M, Ramaekers JG, Evers EAT, Riedel WJ. 2006. Serotonin and human cognitive performance. Curr Pharm Des 12: 2473-2486. 
Seifritz E, Baumann P, Muller MJ, et al. 1996. Neuroendocrine effects of a $20-\mathrm{mg}$ citalopram infusion in healthy males. A placebo-controlled evaluation of citalopram as 5-HT function probe. Neuropsychopharmacology 14(4): 253-263.

Siwek DF, Pandya DN. 1991. Prefrontal projections to the mediodorsal nucleus of the thalamus in the rhesus monkey. J Comp Neurol 312(4): 509-524.

Soubrie P. 1986. Reconciling the role of central serotonin neurons in human and animal behavior. Behav Brain Sci 9: 319-364.

Spoont MR. 1992. Modulatory role of serotonin in neural information processing: implications for human psychopathology. Psychol Bull 112(2): 330-350.

Sturm W, Willmes K. 2001. On the functional neuroanatomy of intrinsic and phasic alertness. NeuroImage 14 (1 Pt 2): S76-S84.

Talairach J, Tournoux P. 1988. Co-planar Sereotaxic Atlas of the Human Brain. Thieme Medical: New York.
Teichner WH. 1974. The detection of a simple visual signal as a function of time of watch. Hum Factors 16(4): 339353.

Vollm B, Richardson P, McKie S, Elliott R, Deakin JF, Anderson IM. 2006. Serotonergic modulation of neuronal responses to behavioural inhibition and reinforcing stimuli: an fMRI study in healthy volunteers. Eur J Neurosci 23(2): 552-560.

Wingen M, Kuypers KPC, Ramaekers JG. 2006a. The role of 5-HT1a and 5-HT2a receptors in attention and motor control: a mechanistic study in healthy volunteers. Psychopharmacology DOI:10.1007/s00213-006-0614-X

Wingen M, Kuypers KPC, Ramaekers JG. 2006b. Selective verbal and spatial memory impairment after 5-HT1a and 5-HT2a receptor blockade in healthy volunteers pretreated with an SSRI. $J$ Psychopharmacol DOI:10.1177/ 0269881106072506 